\title{
APPLICATION OF 7S METHODOLOGY: A SYSTEMATIC APPROACH IN A BUCKET MANUFACTURING ORGANISATION
}

\author{
N. Sukdeo ${ }^{1 *}$, K. Ramdass ${ }^{2} \&$ G. Petja ${ }^{1}$
}

\section{ARTICLE INFO}

\section{Article details}

Submitted by authors 11 Nov 2019

Accepted for publication 9 Nov 2020

Available online $\quad 14 \mathrm{Dec} 2020$

\section{Contact details}

Corresponding author

nsukdeo@uj.ac.za

Author affiliations

1 Department of Quality and Operations Management, Faculty of Engineering and the Built Environment, University of Johannesburg, South Africa

2 Department of Mechanical and Industrial Engineering, University of South Africa, South Africa

\section{ORCID® identifiers}

N. Sukdeo

https://orcid.org/0000-0003-4126-9682

K. Ramdass

https://orcid.org/0000-0001-5480-3368

G. Petja

https://orcid.org/0000-0002-8120-1773

DOI

http://dx.doi.org/10.7166/31-4-2283

\section{ABSTRACT}

While the initial 5S methodology focused on sorting, cleaning, standardising, and sustaining the work environment, $7 \mathrm{~S}$ is a new methodology that has been modified to incorporate a culture of safety and team spirit. The paper describes the application of $7 \mathrm{~S}$ methodology as a systematic approach to increasing efficiency, quality, and safety performance in modern manufacturing organisations. The 7S approach sets the stage for effective lean manufacturing and continuous improvement efforts, stressing a tidy, safe, and organised working environment. The systematic application of $7 \mathrm{~S}$ requires the application of international standards such as OHSAS 18001 to improve employees' occupational health and safety. The case organisation in the study produces buckets for the construction industry. The study's findings revealed the elimination of production problems such as delays, underused space, and nonconformance to safety measures through a holistic application of $7 \mathrm{~S}$. $7 \mathrm{~S}$ also correlates with operational performance - explicitly those aspects of operational performance which influencing the overall quality and productivity of the organisation.

\section{OPSOMMING}

Die oorspronklike 5S-metodologie het gefokus op sorteer, skoonmaak, standaardiseer en handhawing van die werksomgewing. $7 \mathrm{~S}$ is egter 'n nuwe metodologie wat aangepas is om 'n kultuur van veiligheid en spangees te bevorder. Hierdie artikel beskryf die toepassing van die 7S-metodologie as 'n sistematiese benadering om doeltreffendheid, gehalte en veiligheid te verbeter in moderne vervaardigings-organisasies. Die 75 benadering skep die milieu vir 'n doeltreffende lenige vervaardiging en 'n kontinu verbeterende werksomgewing. Die sistematiese toepassing van $7 \mathrm{~S}$ vereis die toepassing van internasionale standaarde soos OHSAS 18001 om werknemers se beroepsveiligheid te verbeter. 'n Emmer vervaardiger in die konstruksiebedryf word as gevallestudie voorgehou. Die gevallestudie se bevindinge toon dat die afskaffing van produksie probleme soos vertragings, onbenutte spasie en nienakoming van veiligheidsmaatreëls behaal is deur die omvattende toepassing van 7S. 7S korreleer ook met operasionele vertoning, spesifiek die aspekte van operasionele vertoning wat die algehele gehalte en produktiwiteit van 'n organisasie beïnvloed.

\section{INTRODUCTION}

The pace of industrialisation and modernisation has left organisations, especially those in manufacturing, immersed in continuous improvement (kaizen) techniques. The key to survival in this industrialised era is to gain competitive advantage and continuously to improve product quality and the safety of employees [1]. These improvement initiatives are often achieved through the application of best quality practices. One of the quality practices for improvements is 5S methodology. The 5S methodology is a tool to enhance continuous improvement of lean manufacturing processes and, as a lean methodology, it is to institute a highly efficient, clean, and safe working environment [2]. 
5S is a Toyota Production System (TPS) technique applied in service and manufacturing organisations, mostly in manufacturing organisations [3]. This technique stems from Sort, Straighten, Shine, Standardise, and Sustain. 5S methodology helps the organisation to consolidate a workplace for efficiency, and to minimise unnecessary wastage and optimise quality and productivity through intermittent monitoring of the workplace [4]. 5S, when successfully implemented and monitored, would result in a vast productivity enhancement, a tidy working environment, a reduction of unnecessary hazardous materials, a reduction in defects, and an increase in employee satisfaction.

\subsection{Problem statement}

The challenge of disorganised and messy work areas continues to play a very critical role in manufacturing organisations, in that, safety measures, quality standards and operating procedures are likely to be violated. Many organisations have lost productivity, experienced financial losses, as well as injuries due to unnecessary industry accidents and fires, specifically in facilities where there are combustible materials present. Such materials can include petro-chemicals or natural gases. Governmental Occupational Health and Safety Act (OHSA) regularly reprimands organisations that tend to put their employees in working conditions, which violates their rights to safety. This act also holds organisations liable in respect of unnecessary industrial accidents and fires. The bucket manufacturing company under study is facing similar challenges. Therefore, the study was undertaken to ensure that quality performance and safety measures are being employed at the company.

\subsection{Research aim of the study}

The research aim of the study was to assess the application of $7 \mathrm{~S}$ tool, to investigate its application in a bucket manufacturing organisation and to achieve a culture of a clean, safe, productive environment, as well as eliminate unwanted items in the workplace. $7 \mathrm{~S}$ will assist the organisation to, actively detect potential equipment failures before it can occur and assist in the reduction of product defects.

\subsection{Objectives of the study}

The four objectives of the research are as follows:

1. To assess whether defects identified on the inspection line are due to disorganised and unclean work area.

2. To study how 7S technique can be useful in reducing product defects.

3. Institute planning systems and cultures that will help to encourage routine workshop inspections and cleaning of the workplace.

4. To provide recommendations on how to sustain $7 \mathrm{~S}$ methodology and other related lean methods.

\section{LITERATURE REVIEW}

\subsection{Lean manufacturing and $5 \mathrm{~S}$}

Juran and De Feo [5] state that lean manufacturing is a technique of optimising organisational systems by eliminating waste within them: anything that does not add value to the customer or the organisation is considered waste. Further, they contend that developing a lean organisation includes the delivery of products and services by using less of everything: less waste, less human effort, less manufacturing space, less outlay of tools, less inventory, less engineering time to develop a new product, and less motion.

The $5 S$ methodology encompasses creating a culture of a neat and tidy workplace. This includes removing anything that is not required in the workplace, sorting tools and materials, and always keeping the floor clean. Therefore there is a high possibility that waste, such as defects in the products and inventory, could be eradicated when these two techniques are integrated.

\subsection{The five pillars of the $5 \mathrm{~S}$ methodology}

The five pillars of the $5 \mathrm{~S}$ methodology are as follows:

\subsubsection{Sort}

It is the first step of the $5 \mathrm{~S}$ approach, in which the organisation needs to retain what is needed and eliminate unwanted materials from the workplace. These items can be disposed of or recycled [6]. In order to apply the first step, managers need to know what to retain and what to throw away [7]. 


\subsubsection{Set in order}

This second step is to set items in order, to improve the flow of work and easily identify tools and materials [8]. The objective of this step is to arrange the work in an orderly way and to encourage the use of visual aids to reduce the time spent searching for items [7]. Visual management systems (VMS) are commonly used as a way to visualise the walk areas and restricted areas for safety purposes, and use name tags for materials and tools [1].

\subsubsection{Shine}

Once the unwanted items have been removed and the workplace has been set in order, the next step is to tidy and clean up the workplace [7]. This step includes eliminating all forms of dirt, contamination, and untidiness from the workplace. Many organisations enforce this step by outsourcing cleaning services to undertake the daily cleaning of floors and equipment [6], which makes it easier to do preventative maintenance on key equipment and easily identify potentially hazardous factors.

\subsubsection{Standardise}

Without standard operating procedures (SOPs), the organisation will not be able to detect when deviations or variations occur [9]. This step requires the organisation to generate standardised policies, processes, and procedures to enhance an continuous improvement initiative in the workplace [7]. Standardised quality tools such as root-cause-analysis and check-sheets are frequently used as ways to ensure a consistent, standardised performance [10].

\subsubsection{Sustain}

Heizer and Render [6] suggest that, in order for an organisation to ensure an effective culture of neat and tidy workplace, it should intermittently monitor performance to identify deviations. This would help to put measures in place that ensure that progress is sustained.

While $5 \mathrm{~S}$ is widely used, some organisations have chosen to modify the methodology to create $6 \mathrm{~S}$, which includes safety.

\subsection{Safety as the sixth ' $S$ '}

Heizer and Render [6] have extended the methodology of $5 \mathrm{~S}$ to $6 \mathrm{~S}$ by adding employees' safety. Thus one can identify $6 \mathrm{~S}$ as a tool for effective safety management, including the prevention of hazards, fatal accidents, injuries, and deaths [19]. A safe working environment is established by integrating $5 \mathrm{~S}$ with the occupational health and safety assessment series (OHSAS) [12]. Safety is a multi-disciplinary approach to ensuring that an organisation complies with the regulations of the Occupational Health and Safety Act 85 of 1993 (OHSA) [13]. This Act correlates with the 6S methodology, in that the tool emphasises cleaning the workplace and removing unwanted items that are no longer useful to the process, thereby eliminating factors that lead to injuries and fatalities.

\subsection{Spirit as the seventh ' $S$ '}

This step requires the involvement of employees in the workplace. Thus teams are encouraged to meet regularly to discuss issues relating to $7 \mathrm{~S}$ - and specifically those in their work area [11].

As leaders understand the impact of organisational culture and the crucial element of respect for employees, choosing to include 'spirit' as the seventh step of the methodology highlights support for the people factor in the workplace [14]. The 7S methodology is adopted by an organisation to promote a culture of teamwork and to improve employee morale and productivity. It creates a culture of team spirit. The mere implementation of the $7 \mathrm{~S}$ methodology is not sufficient: it requires the continuous monitoring, evaluating, and controlling of all seven phases to ensure a conducive working environment and so to increase productivity and enhance performance and efficiency [20].

\subsection{The evolution from 5S to 7S methodology}

Enhancing productivity, performance, and efficiency is a continuous improvement initiative for most organisations. $5 \mathrm{~S}$ practices had been significantly adopted in manufacturing organisations, and had contributed to enhanced performance and efficiency, thus mitigating risks, injuries, and fatalities. The $6 \mathrm{~S}$ methodology extended $5 \mathrm{~S}$ to sustain an ergonomically conducive working environment for employees. The $7 \mathrm{~S}$ methodology added further to the $6 \mathrm{~S}$ methodology, with spirit forming the seventh stage, in which senior management and employees cooperate to promote a culture of teamwork and continuous improvement. While most organisations have successfully implemented the $5 \mathrm{~S}$ and $6 \mathrm{~S}$ initiatives, the addition of spirit was to emphasise reliance on the human factor as crucial to the quality of performance and efficiency in an organisation [20],[21]. 
The research used quantitative analysis to investigate how the 75 methodology has affected the number of defects in manufactured products. The research defined the following research question:

In what ways does a disorganised and unclean workplace have an impact on defective and non-conforming products?

The study focused on the buckets produced by a manufacturing company for construction excavators. This company was suitable for the study because a wide range of defects, such as cracks and dirt detected during inspection, could be eliminated using the $7 \mathrm{~S}$ methodology.

The company has five production workshops: the stamping shop (SS), bucket shop (BS), trim shop (TS), paint shop (PS) and final inspection bay (FIB). The final inspection bay plays a vital role in ensuring the quality of the buckets produced. The production line is divided into two clear categories: the tester line, and the bucket evaluation standard (BES), which is the line before shipping. In summary, during a normal week of production, the demand is for five buckets per week. However, owing to the number of cracks, scratches, and paint drops, and the amount of dirt, caught in the inspection line, the demand for five buckets per week is frequently not met, with production reduced to a rate of three buckets per week. When asked why weekly targets are frequently not met, one of the quality inspectors stated:

Due to [a] disorganised and dull working area, unnecessary movements are encountered, and defects like un-removable dirt, cracks as well as visible scratches are [an] everyday topic at the inspection bay. This leads to most of the buckets being rejected for rework, even though there have been initiatives to clean and straighten the environment regularly.

\subsection{Sampling technique}

This study used a probability sampling technique. The sample was chosen by selecting a random sample of a suitable number of operators and workstations for observation, and was audited using the $7 \mathrm{~S}$ audit checklist. Production line inspectors were selected. They were provided with defects check sheets to record the number of defects occurring on the production line, and to identify the workshops in which the defects occurred. Hynan and Sierra [15] state that check sheets and checklists are good for quantitative research because respondents are required to select answers from a set of alternatives, and so will not experience difficulties.

\subsubsection{Sampling areas}

The bucket manufacturing company is moderately automated, with five production workshops (identified earlier) that are involved in the intensive production of buckets for construction excavators. There are specific workstations in each workshop where small parts are built and assembled to produce a single bucket. For instance, in the bucket shop (BS), six workstations are responsible for the following:

a) Measuring the width and length of the steel sheets to be used.

b) Cutting the steel sheets according to the recommended specifications.

c) Welding the joints of the steel sheets together to make a complete bucket.

\subsection{S audit check list}

The 7S audit is defined as a guideline to evaluate the effectiveness and efficiency of the organisation against a set of housekeeping, safety, and environmental standards [16]. Thus, as modernised manufacturing organisations become increasingly multifaceted, establishing auditing practices has become even more significant for them to ensure sustainability. Immonen [17] emphasised the fourth $S$ (standardisation) as crucial for making it possible and feasible to live up to the stipulated quality, safety, and environmental standards. The South African National Bureau of Standards [12] added that auditing activities are essential if an organisation is to maintain its sustainability by consistently evaluating its effectiveness and efficiency against quality, environmental, and safety standards.

The 75 audit checklist was used in this study as an instrument to collect data related to the activities and processes of the workplace. The checklist in Annexure 1 was used to audit and monitor the necessary processes in selected workstations, using the Likert scale. 
The 7S audit was conducted before and after the application of the methodology at the company. Table 1 shows how the researcher scored the selected departments and workstations, based on the four categories of the Likert scale.

Table 1: 7S scoring technique

\begin{tabular}{|l|l|}
\hline Score & Description \\
\hline Poor & $\begin{array}{l}\text { Unwanted items are lying all over the place, the workplace appears disorganised, the floor and } \\
\text { machines appear dirty, and there are spillages on the ground. }\end{array}$ \\
\hline Fair & $\begin{array}{l}\text { Workers are showing a culture of cleaning after work, and ensuring that everything is in its place, by } \\
\text { removing unwanted items on the shop floor and eradicating spillages on the ground. }\end{array}$ \\
\hline Good & $\begin{array}{l}\text { Materials are easily recognisable and equipment / tools that are used frequently are stored } \\
\text { accordingly. Materials are stored in shelves with name tags for quick identification. There are } \\
\text { demarcation lines for safety and comfort purposes. The workplace floor is shiny, and production } \\
\text { equipment is inspected regularly / according to maintenance intervals. }\end{array}$ \\
\hline Excellent & $\begin{array}{l}\text { People are provided with training in standard operating procedures and the 7S methodology; there is } \\
\text { adequate support from the top management; higher productivity is achieved owing to fewer } \\
\text { unnecessary movements; a reduced number of defects in the products are found owing to an organised } \\
\text { working area; and the number of workplace injuries is reduced. }\end{array}$ \\
\hline
\end{tabular}

\subsection{Daily defects check sheet}

A check sheet is one of seven quality control (QC) tools, and is meant to record simple facts and statistics on the shop floor over a specified period of time [18]. Heizer and Render [6] state that the check sheet is a form that is designed to record data that can be used for any statistical analysis in order to identify deviations and generate improvements. Check sheets assist the researcher to find the facts and patterns that aid subsequent analysis [6].

In this research project, a check sheet was used on the inspection line to collect daily defects over a period of two months. Therefore the check sheet form was designed to include the defects' description, the department in which the identified defects might be arising, the time at which the defects occurred, and the frequency of the defects.

\section{FINDINGS OF THE STUDY}

\subsection{S Audit results}

The operational activities of the company were observed, and the performance was scored using the $7 \mathrm{~S}$ audit checklist for a period of five days for each of the workshops. The first $7 \mathrm{~S}$ audit was conducted before the application of the 7S methodology. This audit was conducted mainly to identify the factual reasons for the application of $7 \mathrm{~S}$ at the company.

The application process started at the stamping shop, where the steel sheets from the supplier are stamped and given different shapes that will then be transferred to the bucket shop for welding and connecting the joints to make the bucket. Thereafter the buckets are transferred to the trim shop, where bucket tips are welded on to the bucket and weld splatters are checked and removed with a steel brush. The bucket then goes to the paint shop to be painted with different colors, according to the requirements of customers. The bucket is then sent to the inspection bay for the inspection of the final product.

The audit conducted at the workshops showed that the stamping shop performed poorly on 'organised and clean workplace', scoring a total $7 \mathrm{~S}$ performance of 49 , with an average $(\bar{x})$ of 1.4 per $\mathrm{S}$ principle (sort, set in order, shine, standardise, sustain, safety and spirit). The paint shop had a slightly higher performance score of 54 , with an average $(\bar{x})$ of 1.54 per $S$ principle. The bucket shop performed moderately well with a $7 S$ performance of 59 and an average $(\bar{x})$ of 1.69 per S principle. The trim shop had the second highest score with a $7 \mathrm{~S}$ performance of 65 and an average $(\bar{x})$ of 1.86 per $S$ principle. The final inspection bay performed the best with a total 75 performance of 77 and an average $(\bar{x})$ of 2.20 per S principle.

'Best performance' means that the working area meets the required 7S standards of a clean working area, the removal of anything that does not add value, and an indication of safety lines and signs. The table below summarises the $7 \mathrm{~S}$ audit performance per workshop before application, together with the $7 \mathrm{~S}$ principles averages per workshop. 
Table 2: Summary of the first 7S audit performance, before application

\begin{tabular}{|l|c|c|c|}
\hline \multicolumn{1}{|c|}{ Workshop } & Total performance & Performance & Average performance \\
\hline Stamping shop & 50 & $16 \%$ & 1.40 \\
\hline Paint shop & 61 & $20 \%$ & 1.54 \\
\hline Bucket shop & 55 & $18 \%$ & 1.69 \\
\hline Trim shop & 65 & $21 \%$ & 1.86 \\
\hline Final inspection bay & 77 & $25 \%$ & 2.20 \\
\hline TOTAL & 308 & $100 \%$ & 1.74 \\
\hline
\end{tabular}

\subsection{Detailed performance per workshop}

The pie charts below show in detail the performance of each workshop on each $\mathrm{S}$ principle of the $7 \mathrm{~S}$ methodology.

\subsubsection{Paint shop}

Figure 1 indicates that the paint shop did not sort or separate needed items from unwanted items; there was no evidence of the workshop being regularly cleaned; and methods of housekeeping were not sustained, at 13 per cent. Therefore, poor sustainability at this workshop meant that it failed to cover the following points:

- $\quad$ Adequate visual management system in place

- $\quad$ Evidence of good team-building in the workshop

- Up-to-date operating procedures for the workshop

- Up-to-date lean daily management boards to encourage weekly or daily $7 \mathrm{~S}$ and lean meetings

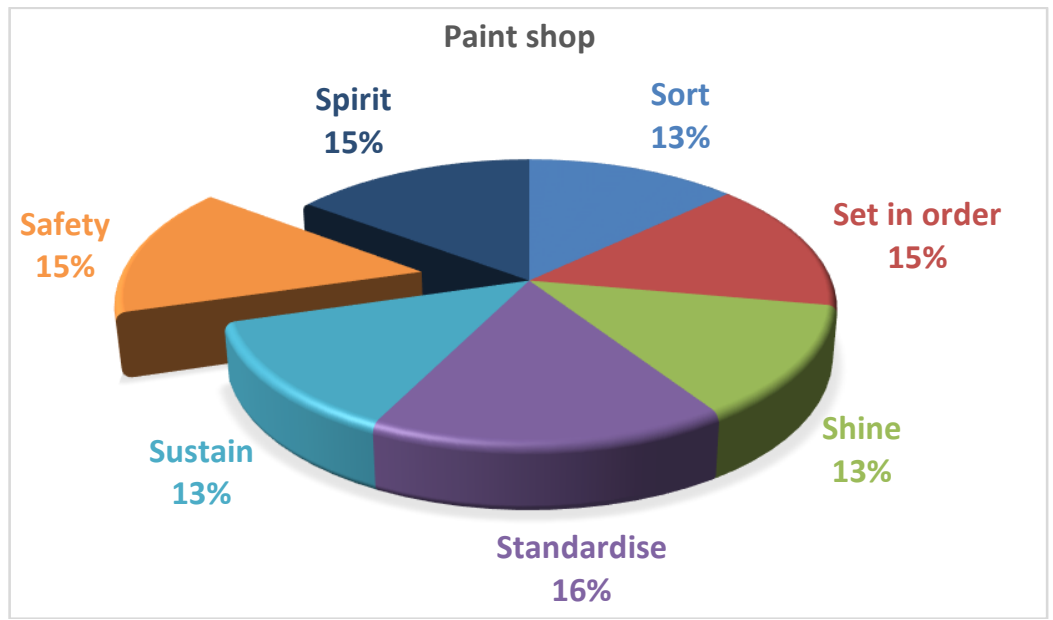

Figure 1: 7S performance at paint shop

In addition, to achieve a sustainable workshop performance, the points stipulated above should be adopted, as they would ensure that the $7 \mathrm{~S}$ methodology becomes routine and part of its culture.

\subsubsection{Trim shop}

The 7S performance in the trim shop is illustrated in Figure 2 below. Setting items in order appears to be a challenge in this workshop, with a performance of 12 per cent. Therefore the researcher was given the task of developing strategies to ensure that 'set in order' was improved in the paint shop and in the trim shop by updating their operating procedures, encouraging daily lean and $7 \mathrm{~S}$ meetings, and finding ways to improve the workshops' overall performance. 


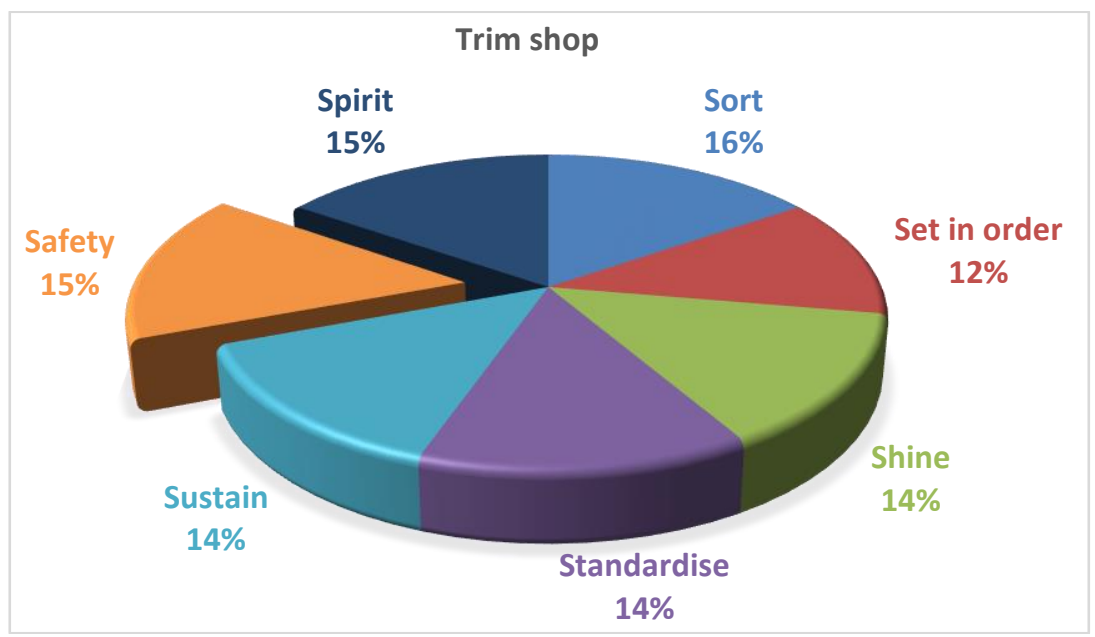

Figure 2: 7S performance at trim shop

\subsubsection{Bucket shop}

The 7S performance at the bucket shop is illustrated in Figure 3 below. The 'shine' phase of the $7 \mathrm{~S}$ appeared to be a challenge for this workshop, with a performance of 12 per cent. The poor performance in the 'shine' phase meant that:

- $\quad$ Floors were not cleaned; rather, they are full of waste and water and oil spillages, which might have led to injuries and industrial fires.

- $\quad$ The machines used in this workshop were dirty, not cleaned, and full of unnecessary oil.

- $\quad$ There was no evidence of equipment inspections in conjunction with equipment maintenance.

- Nobody was responsible for cleaning and overseeing cleaning operations in this workshop.

- $\quad$ Operators failed routinely to sweep the floors and wipe the equipment after working with it.

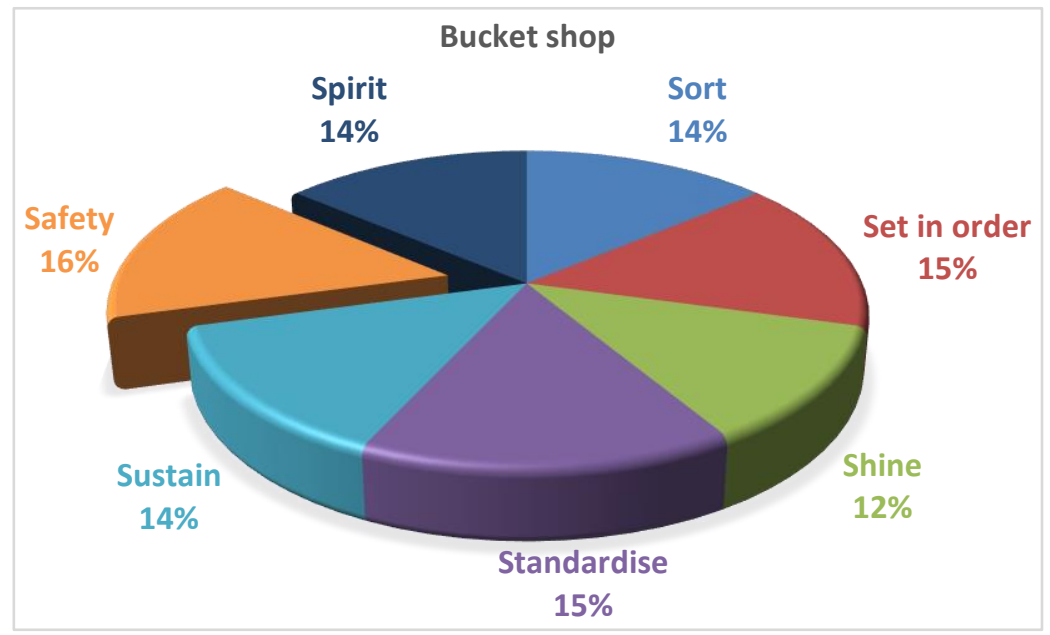

Figure 3: 7S performance at bucket shop

\subsubsection{Stamping shop}

The 7S performance at the stamping shop is illustrated in Figure 4 below. The 'sustainability' phase of the $7 \mathrm{~S}$ appeared to challenge this workshop, with a performance of 12 per cent. The stamping shop performed very well with the other phases. Thus, to ensure sustainability, the workshop should enforce training on the operating procedures, keep the standard operating procedures up to date, and encourage daily or weekly lean and 7S meetings. These meetings would ensure that the other phases of the 7S methodology, such as 'shine' and 'set in order', were fully sustained. 


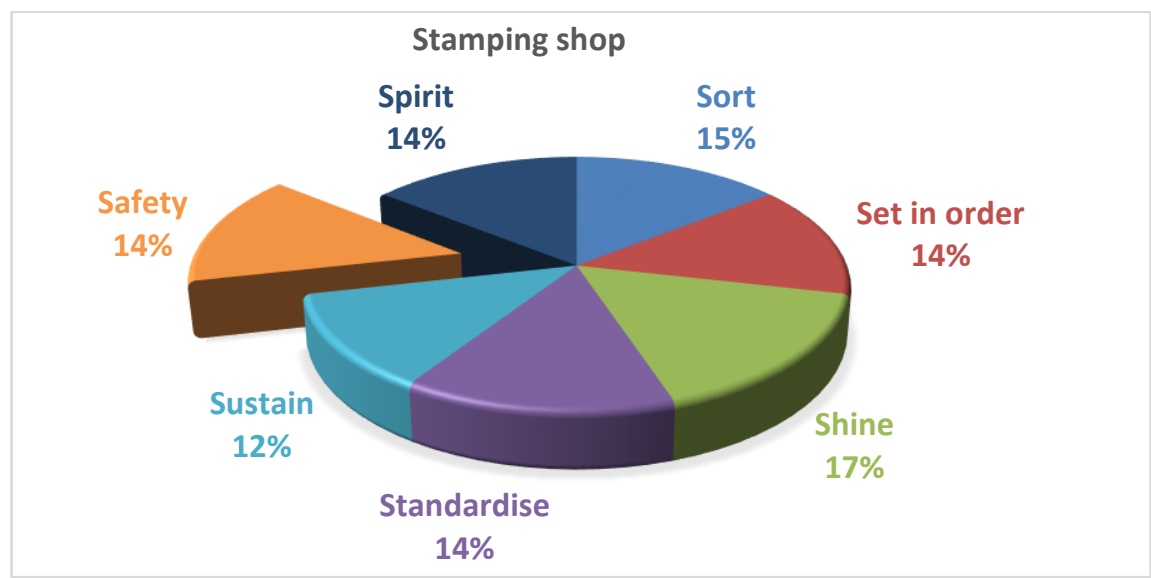

Figure 4: 7S performance at the stamping shop

\subsubsection{Final inspection bay}

The 7S performance at the final inspection bay is shown in Figure 5 below. The 'sustainability' phase of the $7 \mathrm{~S}$ appeared to be a challenge for this workshop, with a performance of 11 per cent. Strategies for sustainability that were devised for the stamping shop, the paint shop, and the trim shop were also used at the final inspection bay to ensure that the $7 \mathrm{~S}$ methodology was adopted to deal successfully with the identified defects and other hazardous matters.

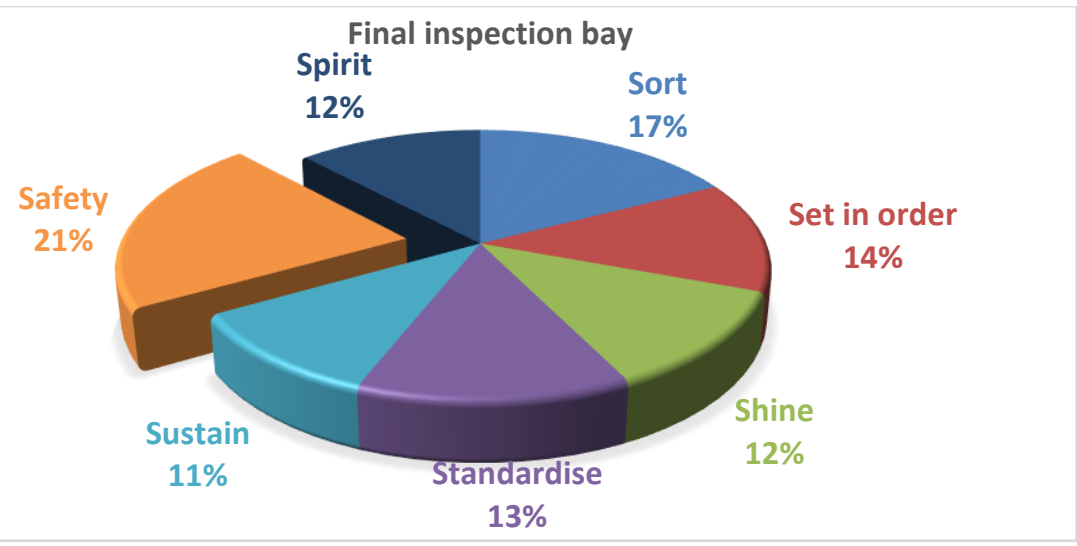

Figure 5: 7S performance at the final inspection bay

\subsection{Overall performance of the 7S methodology}

Table 3 below illustrates the total performance of $7 \mathrm{~S}$ at the bucket manufacturing company. This analysis indicated that the company was performing poorly on 'sustainability' (38), 'set in order' (42), and 'spirit' (42). This pointed to the aspects of the 7S methodology that were most needed by the company. Using the related literature, the researcher was able successfully to implement the phase of $7 \mathrm{~S}$ that were most needed by the company - particularly sustainability, which was required by the trim shop, the painting shop, and the final inspection bay. After the successful application of the methodology, another 7S audit was conducted to identify whether the company had noticed any improvements.

Table 3: Overall performance for $7 \mathrm{~S}$

\begin{tabular}{|l|c|c|c|}
\hline \multicolumn{1}{|c|}{ 7S methodology } & Total score & Average $(\bar{x})$ & Standard deviation \\
\hline Safety & 50 & 10 & 3.54 \\
\hline Sort & 45 & 9.0 & 2.55 \\
\hline Standardise & 44 & 8.8 & 1.1 \\
\hline Set in order & 42 & 8.4 & 1.4 \\
\hline Spirit & 42 & 8.4 & 1.14 \\
\hline Shine & 40 & 8.0 & 1.0 \\
\hline Sustain & 38 & 7.6 & 1.14 \\
\hline
\end{tabular}




\subsection{Identified defects analysis}

Numerous studies of lean management have been conducted, and have proved that the 7S methodology can be used successfully to eliminate product defects. According to Defeo (2016), defects are defined as any identified nonconformity or noncompliance of a specific product, principally after or during the production processes. Juran and Defeo (2010) added that defects are thought of as one of the eight wastes of the lean methodology, to which an organisation turns to find different ways to eradicate identified nonconformities in a product. Table 4 shows the production defects that were identified at the company by using the daily defect check sheet (Annexure 2) that was given to the quality inspectors in the final inspection bay.

The defects were collected over a period of two months, and were classified according to the workshop in which they occurred. Thus different kinds of defects that were caught on the inspection line were logged in the defect check sheet. Defects such as weld splatters, surface level differences (SLDs), scratches, dents, and dirt were given to the researcher. The researcher studied the collected defects thoroughly, and classified them as those that were most probably caused by a disorganised and unclean working environment, and those that were caused by other production factors. Table 4 shows the defects that were the result of an unclean and disorganised working environment.

Based on the defects resulting from an unclean and disorganised working area, the paint shop performed poorly, with a total of 24 defects over the two months, at a defect rate of 31 per cent. The trim shop recorded 20 defects over the two months, at a defect rate of 24 per cent. The bucket shop had many defects - a total of 17 defects over the two months, and a defect rate of 20 per cent. The stamping shop performed moderately, with 16 defects over the two months, and a defect rate of 19 per cent. Finally, the final inspection bay performed extremely well compared with the other workshops, with only eight defects over the two months, at a defect rate of nine per cent.

Table 4: Classification of defects per workshop

\begin{tabular}{|l|l|c|c|}
\hline \multicolumn{1}{|c|}{ Workshop } & \multicolumn{1}{|c|}{ Defect type } & Total number of defects & Defect \% rate \\
\hline Paint shop & Visible rust, scratches, and dents & 24 & $28 \%$ \\
\hline Trim shop & Dents and scratches & 20 & $24 \%$ \\
\hline Bucket shop & Extreme cracks, dirt, and extreme scratches & 17 & $20 \%$ \\
\hline Stamping shop & Irremovable dirt & 16 & $19 \%$ \\
\hline Final inspection bay & Extreme scratches & 8 & $9 \%$ \\
\hline Total & & $\mathbf{8 5}$ & $100 \%$ \\
\hline
\end{tabular}

\subsection{Correlation analysis}

One of the objectives of the study was to identify the relationship between unclean and disorganised working areas and the defects identified in the products. Therefore the company's operations were used in this scenario to demonstrate clearly the correlation between the environment and the defects that occurred. In doing so, the 7S audit was conducted in each workshop, and the number of defects found in the buckets was collected using the daily defect check sheet over a period of two months.

Table 5 summarises the results of the study, which were categorised according to two variables: operating environmental performance and product defects. The defects were regarded as the dependent variable $(y)$ and the operating environment as the independent variable $(x)$. The results show the performance of the operating environment after conducting the $7 \mathrm{~S}$ audit, and the total number of defects in the workshop during a two-month period. The $y$ variable was computed on a rating scale of $1-4$ using the $7 \mathrm{~S}$ audit. The total for each ' $S$ ' is given in Annexure 1.

The operational environment is the score calculated from the audit checklist, such that a higher score signifies a better operational environment that conforms to the $7 \mathrm{~S}$ checklist. This score is calculated as the basis, and represents the independent variable in the regression analysis. The number of defects, which was used to determine the correlation, therefore relates to the operational environment score, and represents the dependent variable. It can be found that, with the underlying assumptions gathered thus far, if the operational environment score increased, then the number of defects would decrease. 
Table 5: 7S performance and defects per workshop

\begin{tabular}{|l|l|l|}
\hline Workshop & $\begin{array}{l}\text { Operational environment } \\
(75 \text { audit }-x)\end{array}$ & $\begin{array}{l}\text { Number of defects } \\
(75 \text { audit }-y)\end{array}$ \\
\hline Paint shop & 61 & 24 \\
\hline Stamping shop & 50 & 20 \\
\hline Trim shop & 65 & 17 \\
\hline Bucket shop & 55 & 16 \\
\hline Final inspection bay & 77 & 8 \\
\hline & 308 & 85 \\
\hline
\end{tabular}

Table 6: Regression summary

\begin{tabular}{|l|l|}
\hline \multicolumn{2}{|c|}{ Regression statistics } \\
\hline Pearson's coefficient $(r)$ & -0.70 \\
\hline Coefficient of determination $\left(r^{2}\right)$ & 0.49 \\
\hline Adjusted R square & 0.31 \\
\hline Standard error & 4.88 \\
\hline Observations (workshops) & 5.00 \\
\hline
\end{tabular}

Table 7: ANOVA

\begin{tabular}{|l|c|c|c|c|r|}
\hline & $D f$ & $S S$ & $M S$ & $F$ & Significance $\boldsymbol{F}$ \\
\hline Regression & 1 & 68.45 & 68.45 & 2.87 & 0.19 \\
\hline Residual & 3 & 71.55 & 23.85 & & \\
\hline Total & 4 & 140.00 & & & Lower 95\% \\
\hline & & & & & -5.18 \\
\hline & Coefficients & Std error & t stat & $P$ & -1.35 \\
\hline Intercept & 41.65 & 14.72 & 2.83 & 0.07 & 0.19 \\
\hline Environmental performance & -0.40 & 0.24 & -1.69 & 0.19 & Significance $\boldsymbol{F}$ \\
\hline & & & & & \\
\hline
\end{tabular}

In Table 6, Pearson's correlation coefficient $(r)$ was found to be -0.70 . The negative value of $r$ indicates a very strong negative relationship between operating environment and number of defects occurring. A negative correlation coefficient $(r)$ means that, for any two variables $x$ and $y$, an increase or improvement in the operating environment is associated with a decrease in the number of product defects per specific production period.

The regression model formula to quantify whether the operating system at the company really had an impact on the number of defects on the products was:

$$
y=41.65-0.40 x
$$

The $a$-value in the above equation represents the $y$-intercept. That is the point on the $y$-axis where $x=0$. This means that the defects in an operating environment with a poor performance of zero will occur at a rate of 41.65 per period of production.

This means that, if $x$ increases by one defect, then $y$ decreases by 0.40 operational performance units.

\subsection{Reliability analysis}

The 7S audit checklist had a total of 35 audit statements that were used in the five workshops at the company, and Cronbach's alpha was found to be 0.878 . Reliability for this research was calculated for the whole $7 \mathrm{~S}$ audit checklist with the results from the five workshops. Accordingly, there was consensus that the data and the measurement instrument would be reliable and consistent if Cronbach's alpha fell close to 90 per cent or just above 70 per cent. A high Cronbach's alpha means that, if repeated applications of the $7 \mathrm{~S}$ audit could be conducted on the very same working environment issue, the results would be moreor-less the same. The reliability analysis was computed as follows:

$$
\text { Cronbach's Alpha }(\alpha)=0,8776
$$

\subsection{After 7S audit application}

The application of the $7 \mathrm{~S}$ methodology has caused drastic changes at the company through the removal of anything that does not add value on the shop floor in the various workshops; the creation of JIT trolley kits for needed and unwanted items; and encouraging the use of pallets as a base platform for buckets. The application of the 7S methodology has created a culture of keeping all the shop floors well-organised, clean, 
highly effective, and oriented to high quality production. Thus the introduction of the $7 \mathrm{~S}$ methodology at the company resulted in massive improvements that influenced its ability to reach its production targets, and improved health and safety on the shop floor. Each principle of $7 \mathrm{~S}$ has been implemented, and drastic improvements have been realised. The following improvements were documented in the organisation for each 7S principle:

\title{
Sort
}

Unnecessary items were removed

Workshops were released from obstructive items

\section{Set in order}

All items were correctly arranged with JIT trolley kits

The time taken searching for equipment and tools was reduced

\section{Shine}

Machines were serviced and cleanliness was maintained

Work environment was tidy and safe

\section{Standardisation}

All obligatory rules and regulations were adhered to

Cleaning schedules were formally documented and implemented

LDM meetings were conducted regularly

\author{
Sustain \\ Adequate self-control and discipline \\ Cooperation in teams in problem-solving \\ Development of better JIT strategies

\section{Safety} \\ Mandatory safety signs were clearly visible \\ Workspace and floors were clean and clear of unnecessary items \\ Employees were provided with appropriate PPEs
}

\section{Spirit}

Employees were provided with appropriate training on workplace procedures

Employees demonstrated and portrayed positive behaviour toward 7S implementation

Employees' efforts and initiatives were recognised and rewarded

Table 8 below illustrates the 'before' and 'after' of the 7S application. The results confirm that there were enormous improvements in $7 \mathrm{~S}$ performance. The paint shop had improved greatly by 25 per cent, from the rate of 49 to 104 per 75 improvement. The trim shop had improved from the rate of 54 to a rate of 97 per 75 performance, with an improvement of 20 per cent from the previous performance. In the bucket shop, buckets have been aligned properly, as indicated in Table 8 This has led to an improvement of 23 per cent over the previous performance. The $7 \mathrm{~S}$ improvement percentage per workshop was noteworthy: the paint shop improved by more than 25 per cent, followed by the bucket shop at 23 per cent increase. The trim shop was third with an improvement of 20 per cent over the previous $7 \mathrm{~S}$ audit. The stamping shop improved by 17 per cent, and the final inspection bay improved their operating environmental performance by 15 per cent. The final inspection bay did not require much improvement, as it had adopted specific 7S methods from other workshops. The comparisons between the 'before' and 'after' applications of the $7 \mathrm{~S}$ methodology per workshop showed that the paint shop had improved by 55 points over the previous $7 \mathrm{~S}$ audit performance; the trim shop had improved by 43 points over the previous $7 \mathrm{~S}$ audit performance. The bucket shop improved by $507 \mathrm{~S}$ points after the audit, while the stamping shop improved from 65 to $1037 \mathrm{~S}$ points - an improvement of 38. Lastly, the final inspection bay had improved from 77 to $1117 \mathrm{~S}$ points an improvement of 34 points. Thus the paint shop performed better than the other workshops, with $7 \mathrm{~S}$ improvements of 75 points. 
Table 8: Improvement percentages

\begin{tabular}{|l|c|c|c|c|}
\hline \multicolumn{1}{|c|}{ Workshop } & Before 7S & After 7S & Difference & 7S Improvement \% \\
\hline Paint shop & 61 & 104 & 43 & $41.3 \%$ \\
\hline Trim shop & 65 & 97 & 32 & $32.9 \%$ \\
\hline Bucket shop & 55 & 109 & 54 & $49.5 \%$ \\
\hline Stamping shop & 50 & 103 & 53 & $51.4 \%$ \\
\hline Final inspection bay & 77 & 111 & 34 & $30.6 \%$ \\
\hline \multicolumn{1}{|c|}{ TOTAL } & $\mathbf{3 0 8}$ & $\mathbf{5 2 4}$ & & $\mathbf{1 0 0 \%}$ \\
\hline
\end{tabular}

\section{5}

\section{CONCLUSIONS}

The 75 methodology turned out to be a significant contributor to the improved performance of the operating environment and the greater ease with which the production processes were carried out. The aim of the study was to appraise the implementation of the $7 \mathrm{~S}$ methodology and audit the feasibility of its implementation in the bucket manufacturing industry to achieve a culture of a clean working environment, safety for employees, quality of performance, and the elimination of unneeded items on the shop floor. The emphasis was on the quality of performance and products in conjunction with the safety of the workers. Therefore numerous changes were made to the working environment at the company by using the $7 \mathrm{~S}$ principles, and the number of defects were kept to a minimum. The changes made were not limited to the introduction of JIT trolley kits to move needed and unwanted items, but also included the re-alignment and sorting of the bucket shop to create more working space, revising the standard operating procedures, and creating cleaning schedules ('shine').

In addition, the research found that the application of the 75 methodology had a positive impact in all five workshops of the company. The effect of the application of the $7 \mathrm{~S}$ methodology at the company was the creation of organised and clean operating environment in which there is a place for everything and everything is in its place. It is clear that the goal of the 7S methodology is broad and diverse. When it is successfully implemented, the working environment improves and obstructions can be addressed and removed. The lean 7S methodology has become an initiative to be implemented as a continuous improvement tool, and it should be constantly monitored and evaluated.

The 7S methodology is a lean technique that many organisations use to achieve a highly effective workplace that is safe, clean, and well-organised. Thus one of the advantages of the $7 \mathrm{~S}$ methodology is an eagerness to achieve an efficient workplace that ensures the effective prevention of defects and accidents, and the elimination of wasted time searching for tools, documentation, or any other product components.

\section{RESEARCH CONTRIBUTIONS}

The current study was conducted to appraise the practices of the 7S methodology and to discuss its implementation and the feasibility in modern manufacturing industries of achieving a culture of a clean, safe, and conducive working environment, thereby eliminating waste in the workspace. This research introduces the relationship between the defects found in products and the operational environment. These findings demonstrate that the 7S methodology can be implemented in any organisation to enhance the performance of its working environment, and so reduce product defects and increase safety measures.

\section{REFERENCES}

[1] Slack, N., Chambers, S. \& Johnston, R. 2010. Operations management, $2^{\text {nd }}$ ed. Cape Town: Pearson.

[2] Pasale, R.A. \& Bagi, J.S. 2013. 5S Strategy: A workplace improvement lean tool. Journal of Engineering and Technology Research, 1(1), pp. 100-107.

[3] Coetzee, R., Van der Merwe, K. \& Van Dyk, L. 2016. Lean application strategies: How are theToyota Way principles addressed? South African Journal of Industrial Engineering, 27(3), pp. 79-91.

[4] Rai, P. 2016. Effectiveness of 5S application on organisations performance. Abhinav International Monthly Refereed Journal of Research in Management and Technology, 5(2), pp. 1-10.

[5] Juran, J.M. \& De Feo, J.A. 2010. Juran's quality handbook: The complete guide to performance excellence, $6^{\text {th }}$ ed. Hong Kong: McGraw-Hill Global Education.

[6] Heizer, J. \& Render, B. 2014. Principles of operations management: Sustainability and supply chain management, $9^{\text {th }}$ ed. London: Pearson Education.

[7] Agrahari, R.S., Dangle P.A. \& Chandratre, K.V. 2015. Application of 5 S methodology in the small scale industry: A case study. International Journal of Scientific and Technology Research (4), pp. 180-183.

[8] Michalska, J. \& Szewieczek, D. 2007. The 5S methodology as a tool for improving the organisation. Journal of Achievements in Materials and Manufacturing Engineering, (24), pp. 211-213. 
[9] Niebel, B.W. \& Freivalds, A. 2014. Niebel's methods, standards and work design, $13^{\text {th }}$ ed. New York: McGraw-Hill.

[10] Foster, S.T. 2013. Managing quality: Integrating the supply chain, $5^{\text {th }}$ ed. New York: Pearson.

[11] Mobley, R.K., Higgins, L.R. \& Wikoff, D.J. 2008. Maintenance engineering handbook, $7^{\text {th }}$ ed. New York: McGrawHill.

[12] SABS. 2016. Occupational Health and Safety Management Systems (OHSAS) 18001:2011.

[13] The South African Department of Labour. 2004. Occupational Health and Safety Act 85 of 1993. Available from: http: / / www.labour.gov.za [Accessed 08 March, 2018].

[14] Wiesenfelder, H. n.d. Bright hub project management. Available from: https://www.brighthubpm.com/sixsigma/57799-overview-of-the-7s-process-in-lean-six-sigma/ [Accessed 10 October, 2018].

[15] Hynan, M.R. \& Sierra, J.J. 2016. Open- versus close-ended survey questions Available from: https://www.researchgate.net/publication/282249876_Open-_versus_close-ended_survey_questions [Accessed April 25, 2018].

[16] Scheid, J. \& Bowen, R. 2013. Working through a sample 5S check sheet. Available from: https://www.brighthubpm.com/templates-forms/71128-working-through-a-sample-5s-check-sheet/\#imgn_0 [Accessed September 25, 2018].

[17] Immonen, N. 2016. Application of 5S methodology: Case Transval Group. Thesis, Helsinki Metropolia University of Applied Sciences.

[18] Juneja, P. 2018. Check sheet - A basic six sigma tool. Available from: https: / /www.managementstudyguide.com/check-sheet.htm [Accessed 20 July, 2018].

[19] Sukdeo, N. 2017. The application of 6S methodology as a lean improvement tool in an ink manufacturing company. International Conference on Industrial Engineering and Engineering Management 2017, 10-13 December, Singapore.

[20] Joshi, A.A. (2015) A review on Seven S (7S) as a tool of workplace organisation. International Journal of Innovations in Engineering and Technology (IJIET), 6(2), pp. 19-25.

[21] Mahlaha, K., Sukdeo, N. \& Mofokeng, V. 2020. A lean 75 methodology framework to improve efficiency and organisational performance: A review study in an SME organisation. International Conference on Industrial Engineering and Operations Management 2020, 9-12 March, Dubai. 
ANNEXURE 1

COMPANY NAME

WORKSHOP AUDITED

SCORING CATEGORIES

AUDITOR

AREA SUPERVISOR

DATE PERFORMED

\begin{tabular}{l|l|l|l}
\hline \multicolumn{1}{c|}{ 7S METHODS } & NO. & ITEMS/REFERENCE & AUDIT DESCRIPTIONS \\
\hline SORT & \multicolumn{3}{l}{} \\
\cline { 1 - 2 }
\end{tabular}

1 Materials or Parts

2 Machine or equipment

3 Tools a containers

There are no unused machines or equipment on the working area

The working area does not contain any unused tools, containers, dies or similar items

4 Visual control

Unneeded items and materials on the shopfloor can be easily identified

5 Sorting Standards

Some red tagging to classify items is evident and some items have been removed

\begin{tabular}{|c|c|c|c|c|}
\hline & & & \\
\hline & & & \\
\hline
\end{tabular}


16 Layout designs

The layout of the workplace is arranged/designed more rationally to avoid unnecessary movements and injuries

17 Lean Daily Management LDM meetings are held and ideas for workplace improvement (LDM) are generated and acted on

18 Key operating procedures Are standard operation procedures clear, documented and actively used

19 Improvement plan Future operating standards are being considered with a clear improvement plan for the working area

20 The first 3 Ss The first 3Ss (Sort, Set in order and Shine) are being maintaine

\begin{tabular}{|c|c|c|}
\hline SUSTAIN & & \\
\hline & 21 Training & $\begin{array}{l}\text { Everyone is adequately trained in standard operating } \\
\text { procedures }\end{array}$ \\
\hline
\end{tabular}

22 Visual Management System Visua

23 Teamwork Good team discipline is evident

24 Procedures Operating procedures are up-to-date and regularly reviewed

25 LDM boards LDM visual boards are up-to-date and regularly reviewed

16 Layout designs

17 Lean Daily Management LDM meetings are held and ideas for workplace improvement (LDM) are generated and acted on

18 Key operating procedures

19 Improvement plan

20 The first 3 Ss Are standard operation procedures clear, documented and actively used

Future operating standards are being considered with a clear improvement plan for the working area

The first 3Ss (Sort, Set in order and Shine) are being maintaine

SUSTAIN

$21 \quad$ Training

Everyone is adequately trained in standard operating procedures

Visual Management System Visual Management System aid the maintenance of the working (VMS) area

23 Teamwork Good team discipline is evident

24 Procedures

25 LDM boards

\begin{tabular}{|l|l|l|l|l|} 
& & & & \\
\hline & & & & \\
\hline
\end{tabular}


ANNEXURE 2

\section{Audit results before $7 \mathrm{~S}$ implementation}

\begin{tabular}{|c|c|c|c|c|c|c|c|c|c|c|c|c|c|c|c|c|c|c|c|c|c|c|c|c|c|c|c|c|c|c|c|c|c|c|c|c|}
\hline \multirow{2}{*}{ WORKSHOPS } & \multicolumn{5}{|c|}{ SORT } & \multicolumn{5}{|c|}{ SET IN ORDER } & \multicolumn{5}{|c|}{ SHINE } & \multicolumn{5}{|c|}{ STANDARDIZE } & \multicolumn{5}{|c|}{ SUSTAIN } & \multicolumn{5}{|c|}{ SAFETY } & \multicolumn{5}{|c|}{ SPIRIT } & \multirow{2}{*}{ TOTAL } \\
\hline & D1 & $\mathrm{D} 2$ & D3 & D4 & D5 & D1 & $\mathrm{D} 2$ & D3 & D4 & D5 & D1 & $\mathrm{D} 2$ & D3 & D4 & D5 & D1 & D2 & D3 & D4 & D5 & D1 & D2 & D3 & D4 & D5 & D1 & $\mathrm{D} 2$ & D3 & D4 & D5 & D1 & $\mathrm{D} 2$ & D3 & D4 & D5 & \\
\hline SS & 1 & 3 & 2 & 2 & 1 & 2 & 1 & 1 & 2 & 2 & 2 & 2 & 3 & 1 & 2 & 3 & 1 & 2 & 2 & 2 & 1 & 2 & 1 & 1 & 2 & 2 & 1 & 1 & 1 & 2 & 1 & 2 & 1 & 1 & 2 & 50 \\
\hline BS & 2 & 1 & 1 & 2 & 1 & 1 & 2 & 2 & 2 & 2 & 2 & 2 & 2 & 1 & 2 & 2 & 1 & 2 & 2 & 2 & 1 & 1 & 2 & 2 & 2 & 2 & 0 & 0 & 2 & 1 & 2 & 1 & 1 & 2 & 2 & 55 \\
\hline TS & 2 & 2 & 2 & 2 & 2 & 2 & 1 & 1 & 2 & 2 & 2 & 2 & 2 & 1 & 2 & 2 & 1 & 2 & 2 & 2 & 2 & 2 & 2 & 2 & 1 & 2 & 2 & 2 & 2 & 2 & 2 & 2 & 2 & 2 & 2 & 65 \\
\hline PS & 2 & 2 & 2 & 2 & 1 & 2 & 2 & 2 & 2 & 2 & 2 & 2 & 2 & 1 & 1 & 2 & 1 & 2 & 2 & 2 & 2 & 1 & 1 & 2 & 1 & 2 & 2 & 2 & 2 & 2 & 2 & 1 & 2 & 2 & 1 & 81 \\
\hline $\mathrm{FIB}$ & 3 & 3 & 2 & 2 & 3 & 2 & 2 & 2 & 2 & 2 & 2 & 2 & 2 & 1 & 2 & 3 & 1 & 2 & 2 & 2 & 2 & 2 & 2 & 2 & 2 & 3 & 3 & 3 & 4 & 3 & 2 & 2 & 1 & 2 & 2 & 77 \\
\hline TOTAL & 10 & 11 & 8 & 10 & 8 & 8 & 8 & 8 & 10 & 10 & 10 & 10 & 11 & 5 & 8 & 12 & 5 & 10 & 10 & 10 & 8 & 8 & 8 & 8 & 8 & 11 & 8 & 8 & 11 & 10 & 8 & 8 & 7 & 8 & 8 & 308 \\
\hline
\end{tabular}

\section{Audit results after $7 \mathrm{~S}$ implementation}

\begin{tabular}{|c|c|c|c|c|c|c|c|c|c|c|c|c|c|c|c|c|c|c|c|c|c|c|c|c|c|c|c|c|c|c|c|c|c|c|c|c|}
\hline \multirow{2}{*}{ WORKSHOPS } & \multicolumn{5}{|c|}{ SORT } & \multicolumn{5}{|c|}{ SET IN ORDER } & \multicolumn{5}{|c|}{ SHINE } & \multicolumn{5}{|c|}{ STANDARDIZE } & \multicolumn{5}{|c|}{ SUSTAIN } & \multicolumn{5}{|c|}{ SAFETY } & \multicolumn{5}{|c|}{ SPIRIT } & \multirow[t]{2}{*}{ TOTAL } \\
\hline & D1 & $\mathrm{D} 2$ & D3 & D4 & D5 & D1 & $\mathrm{D} 2$ & D3 & D4 & D5 & D1 & D2 & D3 & D4 & D5 & D1 & $\mathrm{D} 2$ & D3 & D4 & D5 & D1 & $\mathrm{D} 2$ & D3 & D4 & D5 & D1 & $\mathrm{D} 2$ & D3 & D4 & D5 & D1 & D2 & D3 & D4 & D5 & \\
\hline SS & 4 & 3 & 2 & 4 & 3 & 4 & 3 & 2 & 4 & 3 & 3 & 3 & 4 & 2 & 4 & 4 & 2 & 2 & 4 & 3 & 2 & 3 & 2 & 3 & 3 & 3 & 3 & 3 & 3 & 3 & 2 & 3 & 2 & 3 & 3 & 104 \\
\hline BS & 4 & 2 & 2 & 4 & 3 & 2 & 4 & 4 & 2 & 3 & 4 & 2 & 3 & 3 & 4 & 4 & 2 & 2 & 4 & 3 & 3 & 2 & 2 & 2 & 2 & 2 & 3 & 3 & 3 & 3 & 2 & 3 & 2 & 2 & 2 & 97 \\
\hline TS & 4 & 4 & 4 & 4 & 4 & 4 & 3 & 2 & 2 & 4 & 4 & 3 & 3 & 2 & 4 & 4 & 2 & 2 & 4 & 4 & 3 & 2 & 2 & 3 & 3 & 2 & 3 & 4 & 3 & 3 & 2 & 3 & 3 & 3 & 3 & 109 \\
\hline PS & 3 & 3 & 2 & 2 & 3 & 4 & 4 & 2 & 2 & 4 & 3 & 3 & 2 & 3 & 3 & 4 & 2 & 2 & 4 & 4 & 3 & 3 & 2 & 2 & 3 & 4 & 3 & 4 & 4 & 3 & 2 & 3 & 2 & 3 & 3 & 103 \\
\hline $\mathrm{FIB}$ & 4 & 4 & 2 & 2 & 4 & 4 & 2 & 2 & 3 & 4 & 4 & 3 & 3 & 2 & 4 & 4 & 2 & 2 & 4 & 4 & 3 & 3 & 2 & 2 & 3 & 4 & 4 & 4 & 4 & 4 & 2 & 3 & 3 & 4 & 3 & 111 \\
\hline TOTAL & 18 & 18 & 12 & 18 & 17 & 18 & 16 & 12 & 13 & 18 & 18 & 14 & 15 & 12 & 18 & 20 & 10 & 10 & 20 & 18 & 14 & 13 & 10 & 12 & 14 & 15 & 16 & 18 & 17 & 16 & 10 & 15 & \begin{tabular}{|l|}
12 \\
\end{tabular} & 15 & 14 & 524 \\
\hline
\end{tabular}

